\title{
Aptamer-Based Radiopharmaceuticals for Diagnostic Imaging and Targeted Radiotherapy of Epithelial Tumors
}

\author{
Sotiris Missailidis $^{1 *}$, Alan Perkins ${ }^{2}$, Sebastião David Santos-Filho ${ }^{3}$, Adenilson de Souza da \\ Fonseca $^{3,4}$ and Mario Bernardo-Filho ${ }^{3,5}$ \\ ${ }^{I}$ Department of Chemistry and Analytical Sciences; The Open University; Walton Hall; Milton Keynes; MK6 7AA; \\ s.missailidis@open.ac.uk; United Kingdom. ${ }^{2}$ Department of Medical Physics; University of Nottingham; \\ Nottingham - UK. ${ }^{3}$ Departamento de Biofísica e Biometria; Instituto de Biologia Roberto Alcantara Gomes; \\ Universidade do Estado do Rio de Janeiro; Av. 28 de Setembro, 87; 20551030; Rio de Janeiro - RJ - Brasil. ${ }^{4}$ Centro \\ Universitário Serra dos Órgãos; Centro de Ciências da Saúde; Av. Alberto Torres, 111; 25964004; Teresópolis - RJ \\ - Brasil. ${ }^{5}$ Instituto Nacional do Câncer; Coordenadoria de Pesquisa Básica; 20230130; Rio de Janeiro - RJ - Brasil
}

\begin{abstract}
In the continuous search for earlier diagnosis and improved therapeutic modalities against cancer, based on our constantly increasing knowledge of cancer biology, aptamers hold the promise to expand on current antibody success, but overcoming some of the problems faced with antibodies as therapeutic or delivery agents in cancer. However, as the first aptamer reached the market as an inhibitor against angiogenesis for the treatment of macular degeneration, aptamers have found only limited applications or interest in oncology, and even less as radiopharmaceuticals for diagnostic imaging and targeted radiotherapy of tumours. Yet, the chemistry for the labelling of aptamers and the options to alter their pharmacokinetic properties, to make them suitable for use as radiopharmaceuticals is now available and recent advances in their development can demonstrate that these molecules would make them ideal delivery vehicles for the development of targeted radiopharmaceuticals that could deliver their radiation load with accuracy to the tumour site, offering improved therapeutic properties and reduced side effects.
\end{abstract}

Key words: Aptamer, radiopharmaceutical, diagnostic imaging, radiotherapy, epithelial tumor

\section{INTRODUCTION}

Our knowledge on cancer has changed dramatically over the last few years and, with it, our approach to diagnosis and therapy. A lot has become known about the causes, onset and spread of the disease, the different features of individual cancers and their origin. Scientific knowledge and technological development are constantly improving the outlook on cancer. Yet, even though prevention methods, through changes in lifestyle, vaccinations etc. can significantly reduce the cancer incidence, there are still going to be cancers, caused by various factors, even if these are spontaneous mutations. Thus, there is clearly a need for improved therapeutic approaches to make these cancers treatable conditions, instead of lifethreatening or debilitating diseases. There is, thus, a continuous effort to develop novel therapeutic approaches, based on surgical improvements and novel chemotherapeutic or radiotherapeutic approaches. These may attempt to improve on previous molecules or techniques, find new ways to target previous targets, deliver radiation more specifically and use different kinds of radiation with improved properties, or generate novel agents that are targeting new markers identified from large proteomics efforts (Missailidis, 2008). 
When chemotherapy first became established, there were predictions that, within a few years, radiotherapy would be a thing of the past. Yet, radiotherapy remains a very successful treatment, both radical and palliative, and is indicated in over $50 \%$ of all cancer cases. Improvements to existing techniques, and development of new ones, are happening at a rapid rate. One of the progress areas in radiotherapy is the use of radiopharmaceuticals and molecular targeted radiotherapy approaches to deliver radiation specifically to the cancer site, improving clinical outcome and reducing side effects.

Radiopharmaceuticals have traditionally only been used when there is a high uptake by a particular part of the body, such as Iodine-131 by the thyroid. Otherwise, the use of a radiopharmaceutical would be dangerous, often causing more damaging than therapeutic effect. So, the majority of radiotherapy approaches are focused on external beam therapy, which is now quite accurate. However, research on new ways of targeting cancers with radiopharmaceuticals is likely to result in the wider use of unsealed source radiotherapy, with the possibility that treatment may be individually tailored to the patient's cancer. Such molecular targeted radiotherapy approaches are evolving into using targeted therapeutics to deliver radiotherapy specifically to the tumour site, where a seed can not be introduced. With the use of appropriate targeting agents, such as antibodies and aptamers, a new generation of targeted radiopharmaceuticals has emerged, with conjugated antibodies already in the market, such as Zevalin, and others in clinical development. Aptamers used as delivery agents for radiotherapy are currently at preclinical stage (Borbas et al., 2007). The development of coupling techniques to such delivery agents led to the use of new chelators and different metals that could emit alpha or beta particles for cancer radiotherapy and can now be directed specifically at the tumour site.

It is not surprising that the above developments in molecular radiotherapy came at a time when the biggest boom in anticancer therapeutics has been in the area of biological medicines. Antibodies and nucleic acid therapeutics have been obtaining FDA approval faster than ever before, and dozens of these reagents are now in clinical trials. Antibodies are the most well-established biological agents, with more than 40 monoclonal antibodies currently in clinical trials against various forms of cancer (Belimezi, 2008). Similarly, various classes of nucleic-acid therapeutics, including aptamers, antisense, antigene and siRNA agents, are also being developed as tumour-specific therapies.

Aptamers are oligonucleotides with a defined conformation that allows them to bind specifically to target molecules, including proteins, peptides, enzymes, antibodies and cell surface receptors (Bacher and Ellington, 1998). Aptamers vary in size between 25 and 50 bases and are identified from combinatorial libraries through selective targeting and affinity maturation. They offer unique benefits compared to other targeting agents, in that they bind with high affinity and selectivity, are easily and quickly synthesised using in vitro techniques, are stable and consistent (Jayasena, 1999), making them alternatives to antibodies and peptides for diagnostic assays (Hesselberth et al., 2000; Ferreira et al., 2008). As aptamers are not immunogenic or toxic, they also have potential as therapeutic and imaging agents (Borbas et al., 2007). Aptamers have been primarily used for their ability to act as inhibitors by binding to specific receptors, thus blocking a cellular pathway, which has led to clinical trials of aptamers for the treatment of cancer and macular degeneration and the first FDA approval for an aptamer against AMD, named Pegaptanib. The two year safety results demonstrated that all the doses of Pegaptanib were well tolerated and any adverse events were momentary owing to the injection preparation and procedures rather than the Pegaptanib drug (D'Amico et al., 2006). Furthermore, labelled aptamers have been used as antibody mimics in sandwich assays, ELISAs, and Western blots (Bacher and Ellington, 1998; Jayasena, 1999; Morris et al., 1998; Ferreira et al., 2008), and their ability to directly transduce molecular recognition into optical signals. The demonstration that aptamers, either through incorporation of fluorescent bases in the selection process (Jhaveri et al., 2000) or through postSELEX modifications to generate aptamer beacons (Potyrailo et al., 1998), can be used for ligand identification based on detectable changes in the fluorescence emission upon ligand binding indicates their potential as a sensitive detection tool. However, aptamers have not yet reached their full potential, partly because their labelling has not been fully explored, particularly with regards to radio- and MRI labelling that would allow them specific delivery of radiotherapy, with minimised side effects and could significantly increase 
definition in gamma-camera or MRI imaging, by carrying radionuclides or contrast agents respectively, specifically at the disease site.

\section{Aptamers in the Literature}

Aptamers as therapeutic or diagnostic agents in cancer have been recently reviewed (Khan and Missailidis, 2008; Makwana et al., 2008) as has the potential of aptamers as radiopharmaceuticals in the diagnostic imaging and targeted radiotherapy (Perkins and Missailidis, 2007; Missailidis and Perkins, 2007; Ferreira and Missailidis, 2007). Yet, references to aptamers in radiotherapy or as radiopharmaceuticals have been sporadic at best and the field is clearly lacking in development. To evaluate the current state of research in the field of aptamers, alone and in relationship to cancer, therapy, diagnosis, imaging, radiotherapy and radiopharmaceuticals over the past 18 years, since the first aptamer paper appeared, we have used two of the largest scientific databases, PubMed and Web of Science, with some interesting results.

The searches were performed in PubMed (http://www.ncbi.nlm.nih.gov/entrez/query.fcgi)

and the Web of Science in the period 1990 to 2008 using the words: (i) aptamer*, (ii) aptamer* and therapy, (iii) aptamer* and diagnosis, (iv) aptamer* and cancer, (v) aptamer* and imaging, (vi) aptamer* and radiopharmaceuticals, (vii) aptamer* and radiotherapy. The data were obtained on August $14^{\text {th }}, 2008$.

Our analysis of the scientific literature on aptamers since 1990, has been very interesting (see Table 1). First of all, we note that, although the first papers on aptamers appeared almost simultaneously in 1990 by two independent groups, led by Gold and Ellington respectively (Tuerk and Gold, 1990; Ellington and Szostak, 1990), there is no reference on aptamers appearing on either database till 1992. This, however, may be related to the term 'aptamer' not being coined and used widely until later on. Furthermore, although PubMed appears to be more widely accessible, Web of Science presented consistently a larger number of hits on aptamers and additional keywords we searched for, with exception to diagnosis.

Another interesting point identified was that, although cancer is currently one of the most researched scientific areas, only $12 \%$ (according to PubMed) and $\sim 8.3 \%$ (according to the Web of Science) of publications on aptamers are related to cancer. This clearly indicates that aptamers have found wider applications in other areas of research, with only limited attention to their great potential in cancer. Furthermore, few papers are related to aptamers and radiopharmaceuticals or aptamers and radiotherapy.

Table 1 - Papers in PubMed (white) and Web of Science (gray) from 1990 to August 2008.

\begin{tabular}{|c|c|c|c|c|c|c|c|c|c|c|c|c|c|c|}
\hline \multirow{2}{*}{$\begin{array}{l}\text { Year } \\
1990\end{array}$} & \multicolumn{2}{|c|}{ Aptamer* } & \multicolumn{2}{|c|}{$\begin{array}{l}\text { Aptamer* } \\
\text { and } \\
\text { Diagnosis }\end{array}$} & \multicolumn{2}{|c|}{$\begin{array}{l}\text { Aptamer* } \\
\text { and } \\
\text { Therapy }\end{array}$} & \multicolumn{2}{|c|}{$\begin{array}{l}\text { Aptamer* } \\
\text { and } \\
\text { Cancer }\end{array}$} & \multicolumn{2}{|c|}{$\begin{array}{l}\text { Aptamer* } \\
\text { and } \\
\text { imaging }\end{array}$} & \multicolumn{2}{|c|}{$\begin{array}{l}\text { Aptamer* and } \\
\text { Radio- } \\
\text { pharmaceuticals }\end{array}$} & \multicolumn{2}{|c|}{$\begin{array}{c}\text { Aptamer* } \\
\text { and } \\
\text { Radiotherapy }\end{array}$} \\
\hline & - & - & - & - & - & - & - & - & - & - & - & - & - & - \\
\hline 1991 & - & - & - & - & - & - & - & - & - & - & - & - & - & - \\
\hline 1992 & 1 & 1 & 1 & - & - & - & - & - & - & - & - & - & - & - \\
\hline 1993 & 12 & 18 & 1 & - & 2 & 3 & - & - & - & - & - & - & - & - \\
\hline 1994 & 12 & 24 & 1 & - & 2 & 3 & 1 & - & - & - & - & - & - & - \\
\hline 1995 & 18 & 37 & 3 & - & 5 & 9 & 1 & - & 1 & 2 & 1 & - & - & - \\
\hline 1996 & 31 & 48 & - & 1 & 5 & 4 & 5 & - & - & - & - & - & - & - \\
\hline 1997 & 56 & 85 & 3 & 2 & 6 & 8 & 9 & - & 2 & 2 & - & 1 & - & - \\
\hline 1998 & 59 & 86 & 3 & - & 6 & 2 & 3 & 1 & - & 1 & - & 1 & - & - \\
\hline 1999 & 59 & 105 & 8 & 1 & 6 & 9 & 6 & 1 & 2 & 10 & 1 & 1 & - & - \\
\hline 2000 & 91 & 133 & 13 & 3 & 12 & 29 & 7 & 2 & 2 & 5 & - & - & - & - \\
\hline 2001 & 81 & 117 & 9 & 5 & 8 & 15 & 13 & 9 & - & 3 & - & - & - & - \\
\hline 2002 & 107 & 157 & 13 & 6 & 24 & 34 & 14 & 14 & 3 & 11 & 1 & 1 & 2 & 2 \\
\hline 2003 & 122 & 207 & 23 & 11 & 26 & 50 & 17 & 13 & 4 & 12 & 2 & 3 & 1 & 3 \\
\hline 2004 & 157 & 243 & 20 & 9 & 28 & 49 & 13 & 17 & 6 & 15 & - & 1 & 1 & 1 \\
\hline 2005 & 214 & 305 & 35 & 12 & 53 & 70 & 21 & 26 & 6 & 14 & - & 1 & 1 & 1 \\
\hline 2006 & 319 & 413 & 65 & 24 & 100 & 115 & 45 & 55 & 10 & 20 & 2 & 4 & 1 & 5 \\
\hline 2007 & 354 & 484 & 93 & 36 & 102 & 130 & 43 & 51 & 13 & 32 & 3 & 4 & 3 & 4 \\
\hline 2008 & 208 & 404 & 42 & 30 & 46 & 61 & 35 & 47 & 10 & 19 & - & 0 & - & 1 \\
\hline Total & 1901 & 2867 & 333 & 140 & 431 & 591 & 227 & 236 & 59 & 146 & 10 & 17 & 9 & 17 \\
\hline
\end{tabular}

These are spread throughout the years, with one or two papers each year, with the exception of 2007 that saw an increase to 4 papers. Yet, as 3 out of 4 papers are reviews, there seem to be only limited 
research on this field, with only one research paper this year. Given the success of aptamers in disease diagnosis and therapy, their radiolabelling potential remains an unexplored field.

\section{Aptamer Design}

High affinity and specificity aptamers are, primarily, generated via an in vitro selection process referred to as SELEX. However, recently, alternative selection processes have also been developed (Drabovich et al., 2005; Berezovski et al., 2005). The basic SELEX protocol is an evolutionary, iterant stringent process involving a combinatorial library of randomized nucleic acid sequences, with structural variations of more than $10^{15}$ different molecules, flanked by primers that allow PCR amplification. This is subjected to the selected molecular target for a series of events of binding, partitioning of unbound aptamers from the bound, followed by elution and amplification of the bound aptamers, which are subsequently further subjected to the target. This process is repeated for several rounds, typically from 8 to 12 , to obtain, through competitive binding, one or few aptamer sequences with high specificity and affinity to the chosen target. Selected aptamers are cloned and sequenced, to reveal the binding sequences. Many alterations can be made to the SELEX protocol, such as on the approach employed to present the target or the manner in which the aptamer-target complexes are partitioned. Alterations in the presentation of the target can entail a method of counter selection or ToggleSELEX, whereas variations in partitioning include photocrosslinking and capillary electrophoresis (CE) reviewed by Hamula et al. (2006).

\section{Chemistry and Labelling}

Oligonucleotides can now be purchased with a number of modifications from various providers of customised oligonucleotides. Such modifications can facilitate the interaction of aptamers with moieties of interest in labelling and to improve their pharmacokinetic properties. Thus, an amino modification at the aptamer terminus (either 3' or 5 ') can facilitate the interaction of the aptamer with a chelator. Ideally, however, this interaction would be post-labelling of the chelator with a metal (Fig. 1), to avoid losing radioactivity, which, for a metal like technetium-99m that has a $6 \mathrm{hr}$ half life, is a particularly important trait.

\section{Improving Pharmacokinetic Properties}

Two major disadvantages have plagued aptamers since their initial development stage. The first major obstacle has been the degradation of oligonucleotides by nucleases. However, this issue has been resolved by a number of techniques. First of all, DNA aptamers have been shown to be far more resistant to nuclease degradation than their RNA counterparts. Second, modifications at the 3' and/or 5' end of the aptamer can secure nuclease resistance and increase the half-life of the molecule from minutes to hours (Khan and Missailidis, 2008; Makwana et al., 2008). One such easy modification we have used on the design of an aptamer radiopharmaceutical has been an inverted base on the unlabelled end of the aptamer (Borbas et al., 2007).

The second issue is aptamers' pharmacokinetic properties. Aptamers are reasonably small $(\sim 10 \mathrm{kDa})$, hydrophilic molecules that are easily cleared by the kidneys. Whilst this is interesting for diagnostic applications, where the aptamer radiopharmaceutical is cleared from the system rapidly, decreasing any background signal, it is devastating for therapy, where $90 \%$ of the aptamer can wash out in the first $15 \mathrm{~min}$. Thus, pegylation of the aptamer on one end with radiolabelling on the other can quickly and confidently increase the half life of the molecule in serum, whilst conferring nuclease resistance. PEG molecules of various molecular weights have been used with aptamers, but only one with a radiolabelled aptamer (Hicke et al., 2006).

\section{Aptamer Radiopharmaceuticals Concluding Remarks}

Aptamers have a great potential in the disease diagnosis and therapy. They have the ability to bind their targets with unrivalled affinity and specificity, they have shown no side effects in treatments they have already been used, such as the nucleolin or the VEGF aptamer, they have no immunogenicity and, in the case of cancer, great tumour penetration (Borbas et al., 2007). 


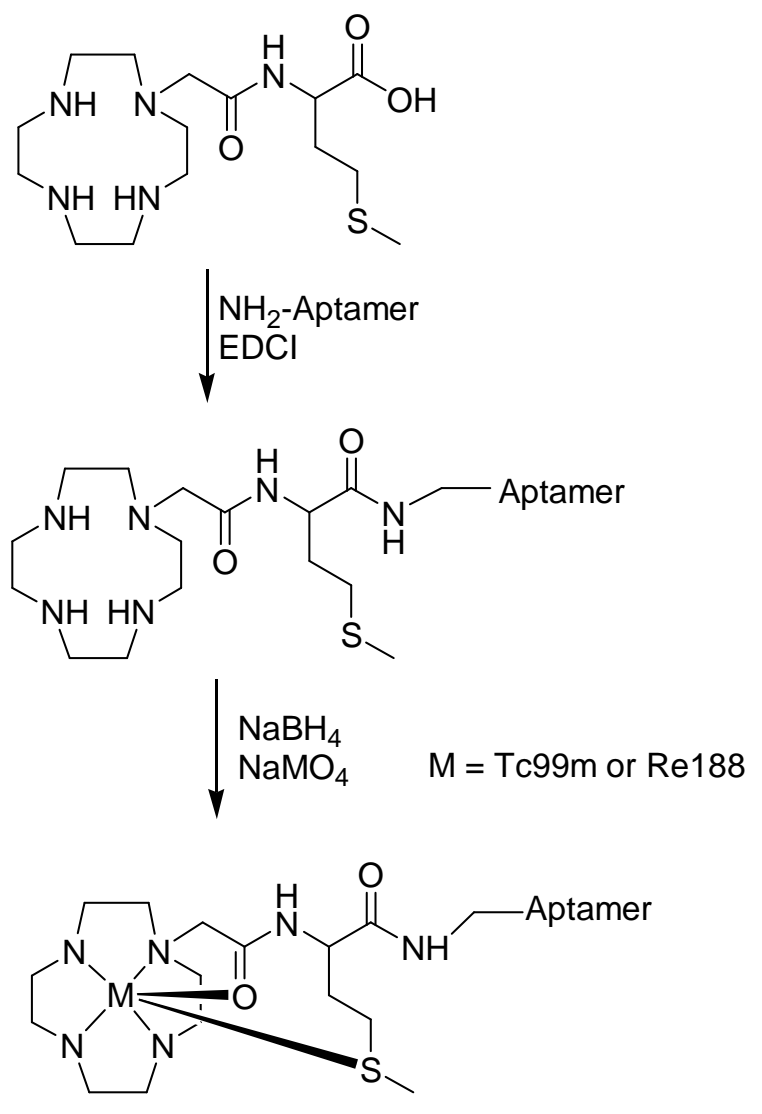

Figure 1 - Post-labelling of an aptamer with a chelator of interest.

Furthermore, through labelling and PEGylation has the possibility to act as diagnostic, imaging or therapeutic agents. A few years ago, an agreement between a major aptamer company and the NCI had been reached to develop and test aptamers against all major known tumour markers. Yet, to this date, only about $10 \%$ of papers on aptamers are related to cancer and only a handful on radiopharmaceuticals. What is particularly interesting, however, is that although there appear to be 2000-3000 papers, the World Intellectual Property Organisation indicates 138 patents in PCT with the world aptamer on the front page, but 3606 patents when searched for aptamer in 'all fields' and 7671 hits on aptamer are found in Free Patents

Online (http://www.freepatentsonline.com/). This is consistent with the great commercial interest of aptamers. Research publications on aptamers as radiopharmaceuticals remain limited and, resulting mostly from research of our group and collaborators worldwide.

\section{ACKNOWLEDGEMENTS}

The authors would like to acknowledge the support of CNPq, FAPERJ, UERJ, The Open University and the Breast Cancer Campaign.

\section{RESUMO}

$\mathrm{Na}$ contínua busca do diagnóstico precoce e melhores modalidades terapêuticas contra o câncer, com base no constante aumento do conhecimento da biologia do câncer, aptâmeros têm a promessa de expandir o atual sucesso dos anticorpos, e superar alguns dos problemas enfrentados com os anticorpos, como agentes terapêuticos ou como agentes que chegam ao processo neoplásico. Entretanto, como o primeiro aptâmero chegou ao mercado como um inibidor da angiogênese para o tratamento da degeneração macular, aptâmeros tem encontrado apenas aplicações ou interesse limitados em oncologia, e ainda menos como radiofármacos para $o$ diagnóstico por imagem e radioterapia direcionada 
para tumores. A química para a marcação de aptâmeros e as opções para alterar suas propriedades radiofarmacocinéticas, para torná-los mais adequados para uso como radiofármacos, é agora disponível e os avanços recentes no seu desenvolvimento podem demonstrar que essas moléculas poderiam ser ideais como veículos para o desenvolvimento de radiofármacos sítiodirigidos que poderiam levar radiação com precisão para o tumor, oferecendo melhores propriedades terapêuticas e reduzidos efeitos indesejados.

\section{REFERENCES}

Bacher, J. M.; Ellington, A. D. (1998), Nucleic acid selection as a tool for drug discovery, Drug Discov Today, 3, 265-273.

Belimezi, M., "Cancer Immunotherapy". In-Anticancer Therapeutics, Missailidis S (editor). Wiley and Sons Ltd, United Kingdom.

Berezovski, M.; Drabovich, A.; Krylova, S. M.; Musheev, M.; Okhonin, V.; Petrov, A.; Krylov, S. N. (2005), Nonequilibrium capillary electrophoresis of equilibrium mixtures: a universal tool for development of aptamers. J Am Chem Soc., 127, 3165-71.

Borbas, K. E.; Ferreira, C. S. M.; Perkins, A.; Bruce, J. I.; Missailidis, S. (2007), "Design and synthesis of mono- and multimeric targeted radiopharma-ceuticals based on novel cyclen ligands coupled to anti-MUC1 aptamers for the diagnostic imaging and targeted radiotherapy of cancer", J Bioconj Chem., 18, 12051212.

D’Amico, D. J.; Masonson, H. N.; Patel, M.; Adamis, A. P.; Cunningham, E. T. Jr.; Guyer, D. R.; Katz, B. (2006), Pegaptanib sodium for neovascular agerelated macular degeneration: two-year safety results of the two prospective, multicenter, controlled clinical trials. Ophthalmology, 113, 992-1001.

Drabovich, A.; Berezovski, M.; Krylov, S. N. (2005), Selection of smart aptamers by equilibrium capillary electrophoresis of equilibrium mixtures (ECEEM). $J$ Am Chem Soc., 127, 11224-11225.

Ellington, A. D.; Szostak, J. W. (1990), In vitro selection of RNA molecules that bind specific ligands. Nature, 346(6287), 818-822.

Ferreira, C. S. M.; Missailidis, S. (2007), Aptamerbased therapeutics and their potential in radiopharmaceutical design. Brazilian Arch Biol Technol., 50, 63-76.
Ferreira, C. S. M.; Papamichael, K.; Guilbault, G.; Schwarzacher, T.; Gariepy, J.; Missailidis, S. (2008), DNA aptamers against MUC1: Design of aptamerantibody sandwich ELISA for early tumour diagnosis, Anal Bioanal Chem., 390, 1039-1050.

Hamaguchi, N.; Ellington, A.; Stanton, M. (2001), Aptamer Beacons for the Direct Detection of Proteins Anal Biochem., 294, 126-131.

Hamula, C. L. A.; Guthrie, J. W.; Zhang, H.; Li, X. F.; Le, X. C. (2006), Selection and analytical applications of aptamers. Trac-Trends Anal Chem., 25, 681-691.

Hesselberth, J.; Robertson, M. P.; Jhaveri, S.; Ellington, A. (2000), In vitro selection of nucleic acids for diagnostic applications Rev Mol Biotechnol., 74, 1525.

Hicke, B. J.; Stephens, A. W.; Gould, T. (2006), Tumour targeting by an aptamer. J Nucl Med., 47, 668-678.

Jayasena, S. D. (1999), Aptamers: An emerging class of molecules that rival antibodies in diagnostics Clin Chem., 45, 1628-1650.

Jhaveri, S.; Rajendran, M.; Ellington, A. D. (2000), In vitro selection of signaling aptamers Nature Biotechnol., 18, 1293-1297.

Khan, H.; Missailidis, S. (2008), "Aptamers in oncology: A diagnostic perspective", Gene Ther Mol Biol., 12, 111-128.

Makwana, V.; Simmons, S.; Missailidis, S. “Aptamers as Anticancer Agents". In-Anticancer Therapeutics, Missailidis S (editor). Wiley and Sons Ltd, United Kingdom.

Missailidis, S., "Future Trends in Cancer Therapeutics". In-Anticancer Therapeutics, Missailidis S (editor). Wiley and Sons Ltd, UK.

Missailidis, S.; Perkins A. (2007), “Aptamers as Novel Radiopharmaceuticals: Their applications and Future Prospects in diagnosis and therapy", Cancer Biother Radiopharmaceuticals, 22, 453-468.

Morris, K. N.; Jensen, K. B.; Julin, C. M.; Weil, M.; (1998), High affinity ligands from in vitro selection: Complex targets. Proc Natl Acad Sci USA, 95, 2902 2907.

Perkins, A.; Missailidis, S. (2007), "Radiolabelled aptamers for tumour imaging and therapy“, Quarterly J Nucl Med Mol. Imag., 51, 292-296.

Potyrailo, R. A.; Conrad, R. C.; Ellington, A. D.; Hieftje, G. M. (1998), Adapting selected nucleic acid ligands (aptamers) to biosensors Anal Chem., 70, 3419-3425.

Tuerk, C.; Gold, L. (1990), Systematic evolution of ligands by exponential enrichment - Rna ligands to bacteriophage-T4 DNA-polymerase. Science, 249(4968), 505-510. 